\title{
DISEÑO DEL PLAN DE DESARROLLO TURÍSTICO DE LA REGIÓN JUNÍN*
}

\author{
Barrionuevo Inca Roca, Yamill'; Aliaga Tabraj, Wilmer² y Soto Cárdenas, Fredy ${ }^{3}$ \\ Facultad de Administración de Empresas de la Universidad Nacional del Centro del Perú.
}

\begin{abstract}
RESUMEN
El trabajo de investigación Diseño del Plan de Desarrollo Turístico de la Región Junín se ha desarrollado orientándolo hacia el desarrollo turístico de la Región Junín, como forma de añadir valor al proceso de desarrollo turístico. El estudio es de tipo descriptivo, y trata de mostrar un diagnóstico de la situación en cuanto a la infraestructura y localización de productos turísticos de la región, para ello se realizaron encuestas a los turistas, para poder medir la percepción de ellos; los resultados obtenidos servirán como base para el proceso de desarrollo de la región. El contenido de las encuestas fueron seleccionados teniendo en cuenta la realidad de la región Junín, así como los estándares mínimos que se deben cumplir para poder estar al nivel de los demás destinos turísticos.La infraestructura turística de la región Junín no satisface los requerimientos de los visitantes. Existen deficiencias que impiden un mejor desarrollo de las actividades turísticas.
\end{abstract}

Palabras clave: infraestructura turística.

\section{DESIGN OF THE PLAN OF DEVELOPMENT TOURISTIC IN THE REGION JUNIN}

\begin{abstract}
The work of investigation "Design for a Tourist Development in the Junin Region" has been developed toward tourist strategies of development in the region, as a way to add value to this process. The present study is a model of descreptive type, and tries to show a situational diagnostic about the infrastructure, localization of tourist products in the region and for this, a survey was made to get informative from the tourists, in order to be able to measure their perception of their own point of view. The obtained results will serve as a base for the processes of its development. The content of the survey was selected considering the minimun reality of junín region, as well as standards which are dire to the fulfilled of being able to satisfy the spectaness acerraling to the levels of the tourist and their destinations The tourist infrastructure in junin region does not satisfy the requirements of the visitors there are many deficiencies that hinder a better tourist development in the region.
\end{abstract}

Key words: tourist infrastructure.

\footnotetext{
* Este trabajo de investigación fue recibido el 20/03/2008 retomado para su revisión el 22/09/2008 y aprobado para su publicación el 27/02/2009.

1. E-mail: a_yamill@yahoo.com

2. E-mail:wilmeraliaga@hotmail.com

3. E-mail: fsotcar@hotmail.com
} 


\section{INTRODUCCIÓN}

Sabemos que un producto turístico está constituido por un conjunto de servicios que giran alrededor de un recurso o varios de ellos, los cuales se ofertan en el mercado nacional o internacional.

Como tendencia general se observa que últimamente las industrias se esfuerzan en ofrecer productos y servicios con un progresivo enfoque a las necesidades individuales del consumidor. En ese sentido se recomienda diseñar productos que contengan una gran variedad de actividades, servicios y experiencias, de tal manera que en un mismo lugar o región, se pueda atraer y satisfacer el individualismo muy variable de su clientela turística.

Esto nos indica que debemos plantear los siguientes objetivos:

- Diseñar nuevos productos turísticos.

- Revalorizar los ya existentes.

- Analizar el conjunto de productos turísticos para constituir el Destino turístico Junín.

En el diseño de un producto turístico no debe primar la pasión y el regionalismo, sino la razón y la planificación en beneficio de la región Junín y de las empresas que van a invertir. Es por esto, que es importante conocer cual es la realidad de los productos que se han estado ofreciendo en la región en los últimos 10 años y cual es la real capacidad de planta turística que existe.

Todo ello para satisfacer la demanda del turista actual quien, ha adquirido tal protagonismo que es reconocido bajo el término "Homo Turisticus", para denotar su comportamiento y sus necesidades. Es importante también para efectos del estudio, incluir un marco teórico previo referido a la terminología utilizada en el sector turístico y además el marco conceptual Porteriano el cual está ligado a la competitividad del sector.

\section{MATERIAL Y MÉTODOS}

\section{Materiales}

En el desarrollo del trabajo de investigación se han recurrido al uso de materiales: bibliográficos, informes, textos, útiles de escritorio, computadora, plumones, lapiceros, papeles, tableros, calculadora, cuestionarios etc.

\section{Método}

Método de investigación no experimental o ex postfactum.

La investigación no experimental es sistemática y empírica; en ella, las variables independientes no se manipulan, porque ya han sucedido; las inferencias de las relaciones entre las variables se realizan $\sin$ intervención o influencia directa, y se observan tal y como se han dado en su contexto natural.

\section{RESULTADOS}

El análisis del entorno relevante para el desarrollo sostenible de la actividad turística de la región Junín muestra que existen importantes amenazas y oportunidades de alto impacto, invalorables para incentivar y desarrollar la actividad turística de manera asertiva.

El análisis interno de la actividad turística de la región Junín, se ha realizado en función a la cadena del valor de la actividad turística y la cadena del valor de los negocios involucrados en el turismo.

Para esto se ha utilizado la metodología del Quántum Performance. Los datos utilizados en el análisis se han tomado mediante la matriz del Quántum Performance y otros han sido recolectados en todo el estudio.

De este modo se ha determinado que el sistema de valor del turismo para la zona está dado del siguiente modo:

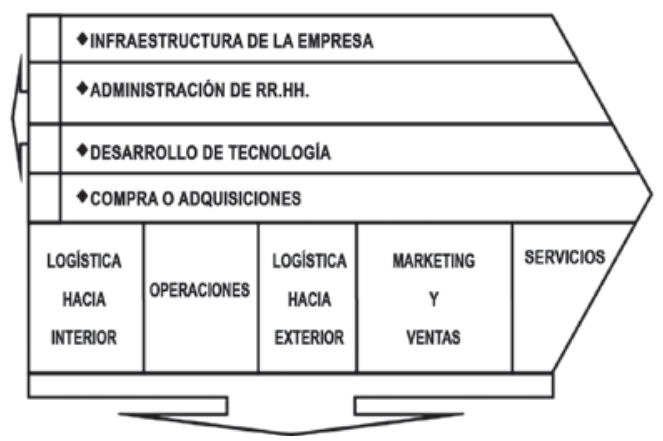

Figura 1. Análisis interno, sistema de valor y cadena de valor. 


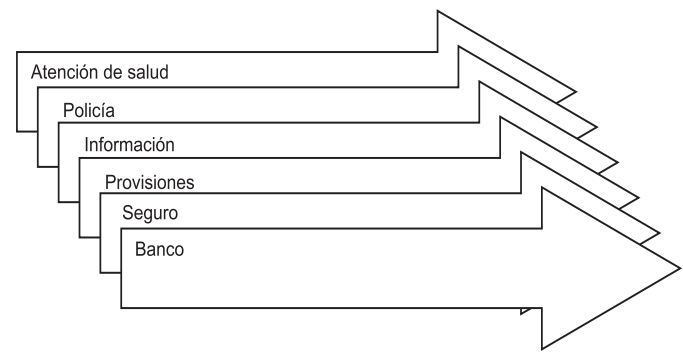

Figura 2. Sistema de Valor del Turismo de la Región Junín.

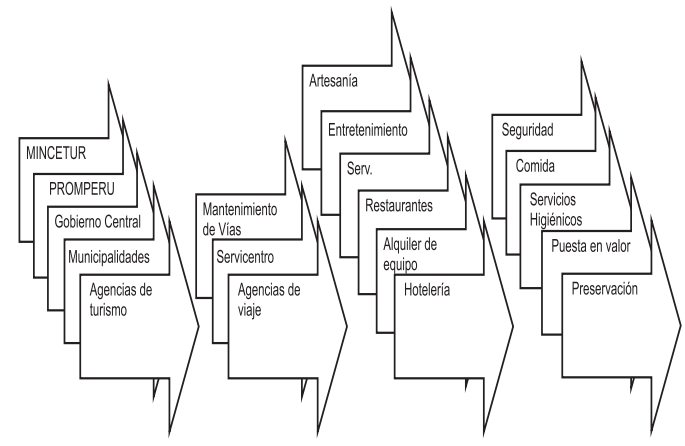

Figura 3. Servicios de Soporte del Turismo de la Región Junín.

\section{Problemática del Sector Turístico}

- Limitado número de visitantes

Aún cuando el país tiene un gran potencial en turismo, el número de turistas internacionales a la República significa el antepenúltimo lugar entre los países del Centro y del Sur de América, seguido por Paraguay y Bolivia.

\section{- Limitado número de sitios turísticos}

Especialmente para visitantes extranjeros, están limitados los sitios turísticos. La mayor parte de ellos sólo visitan Lima, Nasca, Cusco y Machupicchu. Es importante establecer medidas para redistribuir a los visitantes a los sitios turísticos como los de la región Junín.

\section{- Diversificación de productos turísticos}

De acuerdo con el clima, altitud, geografía y cultura, los recursos turísticos en Perú y en particular en la región Junín tienen una gran variedad, siendo importante desarrollar esas opciones para lograr destinos turísticos suficientes.
- Alto costo de viaje comparado con otros países vecinos

Con excepción de pocos países vecinos, se puede decir que viajar a través del Perú, tiene un mayor costo que hacerlo en otros países del Centro y del Sur de América. Más aún se puede observar una carencia de alojamiento de categorías altas e intermedias cuyo costo se encuentra en el rango de US\$ 40 a 60.

\section{PROBLEMÁTICA DE LAS INSTALACIONES TURÍSTICAS}

- Bajas tasas de ocupación en los establecimientos de alojamiento

La tasa de ocupación nacional en alojamiento es cercana al 50 \%; y en Junín alcanza al 32,3 \%.

\section{- Carencia de alojamiento en categorías superiores} Todavía no se han establecido claramente categorías de alojamiento por regiones y clases. La inversión en alojamiento se concentra mayormente en Lima y se puede observar una carencia de inversión en sitios turísticos en todo el país, incluyendo Junín. Adicionalmente y a excepción de Lima, es notable la ausencia de hoteles de 4 y 5 estrellas.

\section{- Uso de edificaciones históricas para alojamiento} Las edificaciones históricas de estilo colonial que se han convertido en alojamientos, son populares entre los turistas internacionales. Es necesario examinar esas instalaciones en los temas de seguridad y comodidad para que puedan convertirse en alojamiento.

\section{- Insuficiente aprovechamiento de museos}

Los museos juegan un papel importante en los atractivos turísticos. Resulta adecuado establecer museos de sitio en los principales recursos turísticos culturales.

- Insuficiente aprovechamiento de las aguas termales

Existen aproximadamente 7 fuentes de aguas termales en Junín. Sin embargo, sólo el $50 \%$ de estos lugares se aprovecha. Para elevar el aprovechamiento de las aguas termales, es necesario preparar las instalaciones adecuadas. 


\section{- Carencia de instalaciones recreativas adaptables}

Es necesario promover el desarrollo de instalaciones que reflejen las características de cada sitio turístico, por ejemplo, el rafting, los kayaks en la cuenca del Perene; el alpinismo, el esquí en las montañas andinas como el Huaytapallana.

\section{Deficientes instalaciones para la transportación terrestre}

En todo Junín se carece de señalización de tráfico vehicular para el uso turístico. Es necesario preparar esta señalización que permita atender las necesidades de los visitantes que se dirigen a los sitios turísticos.

\section{Problemática de la Infraestructura Turística}

\section{Red vial}

Para trabajar en estrecha cooperación entre los diferentes productos turísticos del destino es importante desarrollar la red vial. Es posible otorgar concesiones para las carreteras que requieran inversión.

\section{Líneas aéreas}

Para el caso de la Región Centro, sería adecuado establecer el aeropuerto principal en Jauja aprovechando que este se encuentra rehabilitado completamente. Asimismo, rehabilitar los aeropuertos de Satipo, Mazamari y San Ramón. Conviene también considerar a la ciudad de La Oroya como un futuro aeropuerto.

\section{Tipo de Alojamiento}

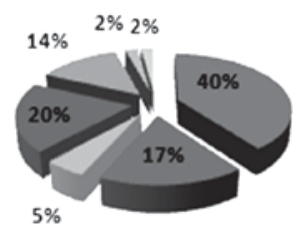

\footnotetext{
- Casa de amigos/familiares

nostal

- Hostal no categorizado

- Casa de Hospedaje

notel

notel no categorizado
}

\section{Suministro de agua}

Se requiere el mejoramiento total del sistema de suministro de agua potable a las instalaciones turísticas en cantidad y calidad adecuada.

\section{Sistema de desagües}

En las áreas donde no se cuenta con desagües, se deben promover sistemas de tratamiento de aguas residuales de acuerdo con las regulaciones vigentes. En Junín este problema es muy grave ya que numerosas ciudades sobre todo del interior y zonas rurales no cuentan con este importante servicio y contribuyen a degradar el medio ambiente.

\section{DISCUSIÓN}

\section{Hoja de posicionamiento}

\section{a. Definición del producto}

"Gran Circuito Centro", es un producto turístico cuyo sustento radica en la existencia de atractivos naturales en la región y los diferentes circuitos turísticos, debiendo ofertar al público con objetividad los beneficios de un buen servicio, recreación, descanso y cultura.

\section{b. Público objetivo}

Todos los turistas que visitan la región Junín y el Valle del Mantaro, de nivel socioeconómico medio entre 25 y 61 años de edad, quienes utilizan paquetes turísticos.

\section{c. Beneficios brindados al consumidor}

- Racionalidad: Salud, descanso, esparcimiento, alimentación y cultura.

- Emocional: Bienestar y satisfacción.

\section{d. Atributos que sustenta los beneficios prometidos}

- El clima de la zona, ampara la promesa de esparcimiento y recreación.

- Los servicios complementarios satisfacen la necesidad de alimentación y descanso.

- Los centros arqueológicos brindan y amplían el beneficio cultural.

\section{e. Categoría del producto}

"Circuito Turístico"

\section{f. Modo y momentos de uso}

Visitas directas en cualquier época del año y toda vez que se visite la Región Junín y el Valle del Mantaro. 


\section{g. Nivel de precios}

Será el mismo ofertado por los actuales paquetes turísticos por introducción, con la diferencia que los visitantes obtendrán mayores beneficios con el uso de circuitos integrados, ya que el producto turístico Junín se encuentra adicionado al producto turístico vendido en el paquete correspondiente.

\section{Estrategias del producto}

\section{a. Estrategia de producto}

Mantener y mejorar los actuales niveles de calidad de los circuitos turísticos.

\section{b. Estrategia de comunicación}

Lanzamiento del posicionamiento enfatizando los atributos más diferenciales de nuestro producto.

\section{c. Estrategia de promoción}

Establecer un sistema de promoción al consumidor a través de costos y beneficios.

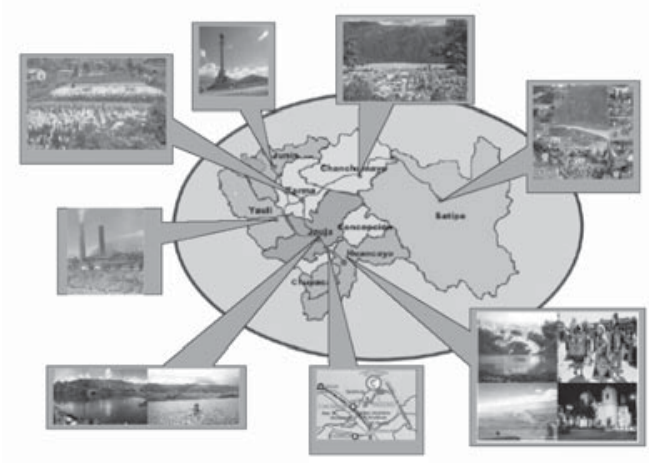

\section{d. Estrategia de distribución}

Lograr el mayor porcentaje de distribución horizontal en las agencias de viaje.

\section{e. Estrategia de precios}

Mantener el nivel de precios de los otros paquetes turísticos resaltando los beneficios obtenidos con el uso de nuestro paquete.

Las empresas dedicadas a la comercialización de productos turísticos "Agencias de Viaje" en lugar de vender un solo producto, deben considerar que tienen entre sus manos otro producto diferenciado que pueda mejorar su oferta.

\section{Posicionamiento del producto}

En el Perú desde el punto de vista turístico, existen competidores del Gran Circuito Centro, entre las que citaremos algunos:

- Ciudad del Cusco.

- Arequipa.

- Huaraz.

- Tumbes

- Ciudadela de Machupicchu.

Cada uno de estos lugares atrae más visitantes al año que el Gran Circuito Centro. ¿Qué es lo primero que viene a la mente cuando se menciona uno de estos productos turísticos?

El problema del posicionamiento radica en ¿cómo se logra crear la imagen visual del Gran Circuito Centro en la mente del cliente en perspectiva?

La búsqueda de la imagen visual es el primer intento para seleccionar entre miles de postales, la imagen que represente perfectamente al "Gran Circuito Centro" captando su esencia pero no se encontró por una buena razón, si hubiera una buena imagen que captara la esencia del "Gran Circuito Centro", ya la habría captado y utilizado alguien, en otras palabras se tendría una imagen posicionada a la par de la imagen del Monumento Arqueológico de Machupicchu.

Entonces la opción más lógica sería tratar de penetrar en la mente del cliente en perspectiva a fin de saber ¿Cuáles imágenes mentales se forman en ella?. Para luego seleccionar la que mejor visualice al Gran Circuito Centro.

¿Cuál es la esencia verbal del Gran Circuito Centro? Un slogan publicitario decía: "Zona Central de los Andes peruanos",

¿Esto nos suena familiar?

¿Nos recuerda algún lugar popular para turistas en el Perú?

Respondiendo a esto, en el Gran Circuito Centro la esencia de la fuerza energética, Junín de los Andes del Perú.

"Gran Circuito de los Andes Centrales del Perú" proporcionan una rápida analogía visual y este circuito 
no pueden darse el lujo de crear una imagen visual a través de los años, en cambio transmitir la imagen mental de los andes del Perú ahorrará una cantidad enorme de tiempo y dinero. Además este concepto diferencia fuertemente al "Gran Circuito de los Andes Centrales del Perú" de otros lugares turísticos.

\section{CONCLUSIONES}

- Se confirma que el elemento más influyente para la decisión del viaje de los turistas son los amigos y familiares, es decir, las recomendaciones directas. Esto ratifica una vez más el esfuerzo que se debe poner en brindar el servicio que espera el turista, $y$ reforzar la idea que el mejor marketing para la venta es el cliente satisfecho que se convierte a su vez en vocero del producto.

- Los recursos naturales de la región, y la biodiversidad existente, la flora y fauna, los criaderos de truchas, aguas termales, lagos y lagunas y los centros nativos, generan un clima favorable para el desarrollo del ECOTURISMO y el turismo de AVENTURA.

- Los recursos en cuanto a infraestructura vial, acceso a los atractivos e infraestructura de alojamientos, señalizaciones, etc. Los turistas requieren COMODIDAD, SEGURIDAD e HIGIENE, sin embargo, sepuedeobservarqueestos conceptos precisamente son los que faltan en la Región, debido a que no existe conciencia turística. En muchas ciudades de la Región no tienen servicios básicos de agua y desagüe. En cuanto a seguridad, los lugares solo tiene postas médicas, no equipadas y con personal limitado. La calidad de servicio que se presta en la Región es muy pobre y por lo general en las épocas altas, lo único que se hace es sorprender al turista con precios exorbitantes y, además, mala calidad de servicio. No existe tampoco una conciencia ecológica que impida el impacto ambiental que el turismo causa, a los atractivos, a la naturaleza y a las comunidades rurales o nativas de la zona y que es necesario minimizar dentro del marco de la ecología y la conservación del medio ambiente.

- Las industrias de apoyo o "clusters" si están presentes pero aislados entre sí y aislados del tema central, el cual es la satisfacción del turista y no la satisfacción de sus expectativas económicas. Hay buena base de hoteles y alojamientos de calidad aceptable y precios razonables (en época baja), así como lugares de diversión y esparcimiento sobre todo en las grandes ciudades como Huancayo, La Oroya, La Merced, Pichanaki, etc. En otros lugares o ciudades pequeñas la realidad es otra. Inclusive el problema del agua caliente que reclaman los turistas es visto como una molestia por los empresarios hoteleros locales.

- En consecuencia la plataforma competitiva turística, es decir, aquellas fuerzas económicas y tecnológicas que catalizan y dinamizan la eficiencia en la utilización de los recursos básicos y avanzados y que constituyen la Productividad de una región, localidad o sector económico son débiles en este sector, lo que se traduce en bajos rendimientos para los negocios turísticos.

- Junín tiene un gran potencial turístico que se puede explotar a través de los circuitos y paquetes turísticos nuevos por tanto debe venderse en este sentido como un paquete global.

- El mercado objetivo nacional es Lima, caso de estudiantes o jóvenes adultos y el mercado internacional es Norteamérica y Europa, para el turismo de aventura y ecoturismo.

- Se cuenta con un gran potencial humano que se puede aprovechar y rescatar.

- Con la promoción de los nuevos paquetes turísticos se lograría incrementar la afluencia turística en las zonas investigadas y por ende lograr un desarrollo económico y cultural de cada lugar.

\section{LITERATURA CITADA}

Acerenza, M.A. 1990. Promoción turística. 3ra. Edición Trillas, México.

Baca, A. A. 1995. Turismo. Lima Impresoras S.R.L.

Borrero, J. C. 1999. Marketing estratégico. Editorial San Marcos, Perú. 
Bote, G.V. 1990. Planificación económica del turismo. México DF Trillas.

Cárdenas, T.F. 1995. Producto turístico. 2da. Edición México. Trillas.

Castany, G. 1984.Tratado práctico de las aguas subterráneas. Edic. Omega.

Fernandez, F.L. 1984. Teoría y técnica del turismo. Tomo I. Edit. Nacional. Madrid.

Ferre, J.M. 2000. Investigación de mercados estratégica. Edit. Gestión. España.

Jacques, L. J. 1996. Marketing estratégico, Edit. Mc Graw Hill España.

Jiménez, M.A. 1995. Turismo, estructura y desarrollo. 2da. Edición. México DF. Mc Graw - Hill.
Kotler, P. y Séller, K. 2006. Dirección de mercadotecnia. Decimosegunda Edición Prentice Hall México.

Ledesma, Carlos A. 2002. Negocios y comercialización Intercultural. Macchi Grupo Editor.

Lovelock, C. H. 2001. Mercadotecnia de servicios. Primera Edición Prentice Hall México.

Océano. 1991. Diccionario.

Plan Maestro de Desarrollo Turístico Nacional en la República del Perú.

Ries, A. T. J. 1998. Posicionamiento. Edit. Mc Graw Hill.

Steven, M.H. 2000. Signos vitales. Edit. Mc Graw Hill, 